\title{
LA PINTURA Y OTRAS FUENTES DE DOCUMENTALES PARA LA CONSTRUCCIÓN DE UN RELATO VISUAL DE LA ALIMENTACIÓN
}

\author{
Gerardo Jesús García Olivares \\ Doctor en Industrias Culturales y de la Comunicación. Universitat Politècnica de València.
}

\begin{abstract}
Looking at painting as other visual sources of documentation to build a visual story about food is of great importance since with them we build an ideology of what current food is and how it has been transformed over time. In rock art, painting, advertising, graphic design, contemporary art, digital creation, we find clear evidence that we ate, how we ate it, and ate it with. This article aims to show that the history of art has been accompanying the history of food and that at present the latter finds in them one of the fundamental bases for the construction of a story that gives consistency to analyzing food in its historical aspect. and that help to build and sustain a story about food widely used in museums dedicated to this topic.
\end{abstract}

Keywords: painting, food history, visual arts, art history.

Resumen: Mirar la pintura como otras fuentes visuales de documentación para construir un relato visual sobre la alimentación es de gran importancia ya que con ellos construimos un ideario de lo que es la alimentación actual y como ha ido transformándose a lo largo de los tiempo. En el arte rupestre, pintura, publicidad, diseño gráfico, arte contemporáneo, creación digital encontramos clara evidencia de que comíamos, como lo comíamos y con comíamos. Este artículo pretende mostrar que la historia del arte ha ido acompañando a la historia de la alimentación y que en la actualidad esta última encuentra en ellas una de las bases fundamentales para la construcción de un relato que de consistencia a analizar la alimentación en su vertiente histórica y que ayudan a construir y sostener un relato sobre la alimentación muy usado en los museo dedicados a este tema.

Palabras clave: museos, pintura, imágenes, historia de la alimentación, artes visuales, historia del arte.

Citar como: Jesús García Olivares, G. (2022). "La pintura y otras fuente de documentales para la construcción de un relato visual de la alimentación". En Actas del III Congreso Internacional sobre Patrimonio Alimentario y Museos. 25-26 noviembre, 2021, Valencia, España. pp. 73-84. https://doi.org/10.4995/EGEM2021.2021.13339 


\section{Introducción}

Los alimentos, su forma de producirlos, la forma de comerlos, el lugar donde se cocinan y se comparten, los objetos con los que se elaboran, sus múltiples combinaciones, la comida como marcador de clases sociales entre otros temas están reflejada en la pintura y en otras artes o técnicas visuales como la pintura, el grabado, los manuscritos y la publicidad. En otras palabras la Historia del arte va de la mano de la Historia de la alimentación y la construcción de una historia de la alimentación se hace por medio de diversas fuentes entre ellas las visuales que da la pintura y otras artes visuales como por ejemplo publicidad. Esto ha sido utilizado en los museos de la alimentación para la construcción de los guiones museográficos construyendo un ideario, esencializado sobre la alimentación de determinadas localidades.

En este artículo se presentarán algunas consideraciones en la utilización de las obras de arte, manuscritos y otras piezas como valor artístico como fuente documental para construir un relato visual de la alimentación tan usados en los museos de la alimentación por medio de la reproducción de obras de arte, esculturas, fotografías y publicidad.

Así la pintura se transforma en documento de determinada época en la que el museo dedicado a la alimentación desea hacer referencia en su relato museográfico sobre la utilización de determinados alimentos. Con estas imágenes se explican hambrunas, crisis alimentarias, recetas o la incorporación de alimentos a la dieta cotidiana. También la distinción social que tenían determinados alimentos o vajillas o enseres empleados en su preparación o las personas que se dedicadas a la producción de esa comida. Para la historia de la alimentación la pintura se transforma en un elemento de constatación de las fuentes escritas o arqueológicas sobre la dieta y la comensalidad. La escultura o la alfarería en forma de monumento o restos arqueológicos sobre la constatación de la producción de determinados alimentos en la zona y la publicidad una forma de entender la velocidad de los cambios en los hábitos alimentarios contemporáneos y sus discursos. No hay que dejar de lado la fotografía de la que también tiene una marcada presencia en los museos relacionados con la alimentación.

Con la invención de la fotografía y su insipiente popularización podemos encontrar en los museos de la alimentación ya sea cuando han hecho recogida de fotos para componer sus exposiciones o han decidido ampliar sus colecciones excelentes documentos que han permitido la constatación de fuentes orales debido a la veracidad que da la fotografía así en muchos museos de la alimentación es posible encontrar representado por medio de fotografías una número importante de acciones dedicada a ese alimento en particular. En otras ocasiones se han hecho recreaciones para poder obtener esas imágenes.

La historia de la alimentación va de la mano de la historia del arte la primera toma la pintura o demás disciplinas artísticas como documento con valor de certificación de determinada realidad ya que las fuentes documentales salvo algunos recetarios ilustrados o sobre todos tratados médicos de le época antigua o medieval son escasos. Ya en la época moderna los recetarios culinarios se hicieron más números y han ido constantemente corroborándose con las obras pictóricas. En el caso de otras fuentes visuales como la publicidad y la fotografía ambas muy presentes en los museos de la alimentación, permiten tener elementos visuales y objetos de gran impacto testimonial sobre como era al alimentación en tiempos recientes y han sido fuentes para disciplinas como la Antropología. 


\section{Objetivos}

Determinar el paralelismo que existe entre representación artística de algunos hechos alimentarios como la llegada de alimentos de las colonias, hambrunas, cambios tecnológico, gustos, ceremoniales o protocolos y otros ejemplos que conforman la historia de la alimentación además de imágenes producto de la publicidad o la fotografía.

Constatar que existe una relación simbiótica entre la Historia del arte y la Historia de la alimentación. Esta última usando la pintura como fuente documental de corroboración y documentación de hechos fundamentales en la historia de la alimentación. Y la primera explicando lo representado por medios de fuentes documentales escritas como recetarios, inventarios, o relatos de las que también se nutre la historia de la alimentación.

También se quiere mostrar como la publicidad y la fotografía fuentes visuales de gran popularización utilizadas en los dos últimos siglos contribuyen enormemente a enriquecer los fondos de los museos de la alimentación contribuyendo a dar una imagen en ocasiones folclorizadas de la cultura alimentaria local.

\section{Desarrollo}

Somos uno mono que cocina, el cocinar nos hizo humano, asegura el primatólogo Richard Wrangham. A esto había agregar que en paralelo al cocinar también se dio el simbolizar y representar alimentos y su forma de obtenerlos. Sin entrar en detalle sobre las dimensiones evolutivas y antropológicas que tiene este proceso ya que no es el objetivo central de este trabajo es posible decir que junto con el registro fósil y arqueológico junto con lo que se representado en el arte, la recolección, obtención elaboración y la comensalidad de los alimentos desde lo inicios de la humanidad hasta la actualidad testimonian como nos hemos alimentados y los profundos cambios que la alimentación ha tenido a lo largo de los siglos.

Entre las representaciones de arte parietal como Las leonas de las cuevas de Chovet, las pinturas de Lascaux o Altamira y los selfis actuales en un restaurante han pasado más de 20.000 años. En ese largo periodo se ha ido recogiendo miles de ejemplos de representación de partes de nuestro sistema alimentario en las artes visuales el que se ha recurrido como fuente para documentar o explicar determinados proceso alimentarios o finalmente para construir una Historia de la alimentación.

Existen varios puntos de inflexión en la Historia de la alimentación y de la Historia de arte que se entrecruzan. Una de las primeras representaciones es el arte parietal que muestra escenas de caza o de recolección de determinados alimentos que se puede considerar el génesis de las representaciones artísticas contemporáneas fueron alimentos.

Las representaciones de la época egipcia son ricas visualmente y permiten la elaboración de un relato visual del comer de esa época. En los enormes frisos se pueden ver personajes sentados comiendo, personas dedicas producción de alimentos como el trigo o representación de comida como las hallada en la tumba de Menna del 1400 aC.

Durante la Época clásica de los simposium griegos por medio de las fuentes escritas nos llegan algunos relatos, pero sobre todo por los mosaicos o las representaciones en la cerámica negra. En estas copas podemos ver la forma de comer, los roles atribuidos a cada uno de los 
participantes, con motivo de que se celebraban. Junto con la cerámica negra uno de los más conocidos es el mural del buceador del Museo Nacional de Paestum del siglo Vac.

De la Antigua Roma nos llega la representación de los desperdicios de los alimentos como el Asàrotos òikos o suelo sin barrer, mosaico confeccionado con pequeñas teselas de pasta de vidrio y esmaltes coloreados. Este mosaico decoraba el suelo de un triclinio en una villa de la época de Adriano, en el Aventino. El tema decorativo ideado por Sosos de Pérgamo es representado en este caso por el artista Heráclito, lo sabemos porque incluyó su firma: "Eraclito fece". Actualmente se encuentra en los Museos Vaticanos y ejemplifica claramente que la comida es retratada por su valor, no solamente por su estética sino como muestra de distinción social. El mosaico es una suerte de trampantojo que quería mostrar la condición social de la familia y la abundancia de sus comidas diarias y las sobras que caían al suelo.

La fuentes arqueológicas sobre todo las relacionadas con la cerámica producto del gran intercambio comercial vivido en el mediterráneo ha sido unas de las principales fuentes de documentación de la alimentación en los tiempos que prosiguieron a la romanización. Se sabe del lugar que ocupaban las cocinas, el utillaje que se dedica a la producción de alimentos o las bases de la alimentación pero las fuentes visuales son escasas. El reciente termopolio un auténtico puesto de comida callejera, hallado en Pompeya en el 2019 en que se pueden ver algunos murales ricos en imágenes como aves, peces y alegorías a la abundancia.

En el Museo del Louvre dentro de los fondos de la cultura árabe se encuentra una miniatura de la segunda mitad del siglo XVI que sugiere la elaboración de la pasta y ha servido para construir un relato un poco forzado sobre los inciertos orígenes de este producto. Los tratados sobre dietética eran importantes en la cultura árabe, pero las ilustraciones que han llegado no son numerosas y no permiten construir una imagen de la alimentación de la época. Aunque de los tratados médicos árabes se han luego traducido e ilustrados obras como el Tacuinum Sanitatis.

Durante la Edad Media los manuscritos y tratados médicos como el fechado en Renania en el siglo XV conocido como el Tacuinum Sanitatis una verdadera recopilación sobre la utilización de alimentos como el aceite de oliva, trufas, perejil o castañas. O el Tacunum de Viena también de origen árabe en que podemos encontrar claras referencias a la elaboración de la pasta son obras de un incalculable valor desde el punto sobre la representación visual de la alimentación hace siglos. Durante la Edad Media la mayoría de las representaciones están centrada en escenas bíblicas especialmente en la Última Cena donde podemos observar tipos de vajillas, distribución y tipo de alimentos. En algunos casos la comida es austera en otros casos copiosa pudiendo ver algunas veces pescados y otras veces carnes como cordero o conejo.

Durante la Edad Media en multitud de obras pictóricas vemos representaciones del vino debido a su valor religiosos. Son muchos lo artistas que dejan verdaderos documentos sobre la producción de vino por medio de representaciones religiosas como se puede observar e en el tapiz The Knights' Banquete del siglo XI ene el Musée de la Tapisserie.

La mayoría de las referencias visuales de la alimentación en la Edad media se centran en los banquetes o en la comida del campesinado, mientras en los primeros podemos observar el tipo de vajilla utilizado, la mantelería y sus plegaturas, la distribución de los invitados y los roles de las personas dedicadas a la producción de alimentos. En los segundos solo vemos comiendo a 
personas con mínimos enceres. Una de la obras también mineada como los tratados anteriormente citados es el Banquete de París de 1378 ofrecido por Carlos V de Francia iluminado por Jean Fouquet Tour entre 1455 y 1460.

El descubrimiento de América junto con la Revolución Industrial son otros de los puntos de inflexión en la relación de la imagen con la comida. El primero supuso todo un choque cultural pero sobre todo una confrontación alimentaria al encontrar el otro alimentario. Las fuentes de la representación de la comida consumida en el nuevo mundo tienen varia fuentes entre las que se puede destacar los manuscritos de historia natural como Francisco Hernández que en 1572 fue enviado por Felipe II para realizar una compilación en materia botánica. Su obra publicada de manera póstuma recoge algunas ilustraciones de los alimentos de la Nueva España como la del jitomate o tomate.

La pintura certifica de tal manera la presencia de los alimentos y su domesticación en el nuevo mundo que el tomate o jitomate recogido por Francisco Hernández entre 1572 y 1574 aparece en la pintura europea recién en 1646 en la obra de Bartolomé Murillo (1618-1682) El sueño de los ángeles que se puede observar en el Louvre en el que se puede observar muy en detalle la presencia del tomate que ya figuraba en la lista de compra de algunos monasterios de Sevilla lo que hace suponer que el tomate había comenzado su andadura de popularización.

Mientras que en Europa la pintura se centraba en algunos casos puntuales en los alimentos a hasta que el bodegón se constituyó un género propio desde las colonias se producían otras obras fuentes visuales como las pinturas de castas esta reproducía los nuevos tipos sociales con los alimentos que estos consumían como si de un taxonomía vegetal y humana se tratase. Entre los siglos XVI y XVII destaca Miguel Mateo Maldonado y Cabrera (1695-1768) pintor novohispano, caracterizado por ser uno de los máximos exponentes de la pintura barroca del Virreinato de Nueva España. E sus pinturas en obras como Mujer mameluca bajo un anacardo fructífero o Hombre mulato con pistola y espada bajo un árbol de papaya. El Bodegón con yuca o el también Bodegón con cocos, piña, papaya y otras frutas entre las que se pueden observar calabazas y melones. También se representaban bananas, guayaba y otras frutas de América. Este tipo de obras no solo pretendían hacer una taxonomía de lo que se entendían que daría como resultado el mestizaje cultural sino que a modo de herbario visual mostraba los productos originarios de las colonias.

Fueron numeroso los naturalistas, viajeros y misioneros que con una amplia vocación científica los que destinados a los territorios recién descubiertos los que construyeron no solo una historia natural de Las Indias sino que esa historia natural en ocasiones eran auténticas recopilaciones de los alimentos y de la forma de comer en el Nuevo mundo. Es de destacar unas de las primeras referencias a productos como la vainilla,o el aguacate de Giovanni Francesco Gemelli Careri (1651-1725), hiciera en el libro Giro del Mundo publicado entre 1699 y 1700. O los llegados de la colonia como la obra Storia Antica del Messico cavata da'mighori storici spagnuoli e da' manoscritti: divisa in dieci libri, de (1780-1781) en que podemos encontrar detalles sobre la elaboración de las tortillas de maíz a partir de la nixtemalización.

Destaca la obra de Guaman Poma de Ayala de 1616 que ilustra Incas cosechando papas, con las técnicas de labrar la tierra propia de la época. Este manuscrito descubierto en 1909 en la Biblioteca Nacional de Dinamarca muestra es un extraordinario documento de gran valor histórico y visual que muestra no con fines estéticos ya que la vocación de Guaman Poma de Ayala no 
era el crear un material artístico sino documentar las características culturales y religiosas que se estaba viviendo en Virreinato del Perú pero la riqueza y la voluntad ilustrativa del autor permite obtener gran información visual de los modos y medios de producción de le época (Figura 1).

Mientras la patata no viajó tan rápido a Europa, los primeros europeos dieron con ella en el siglo XVI en el 1530 cuando llegaron a los altiplanos colombianos como explica en la obra Las primeras cocinas América de Sophie Coe obra de 2004.

La patata Ilegada a manos de Felipe II y luego al Papa Alejandro VII fue más difícil de domesticar, y su incorporación a la dieta y su representación pictórica en Europa fue más tardía. Aparece en herbarios del siglo XVIII algunos elaborados en las colonias y otros en los intentos de las crecientes colecciones botánicas a modo de jardines botánicos que surgían en la Europa de la Ilustración. En la pintura europea, la representación de la patata llega tardíamente desde la icónica obra de Los comedores de patatas de Vincent Van Gogh (1853-1890) pintada en 1855 luego le siguió el Bodegón con patatas y plato amarillo de 1888 luego podemos encontrar obras como la del suizo Albert Anker (1831-1910) Niña pelando patatas.

Hay que destacar en tierras americanas artistas como el holandés Albert Eckhout (1610-1664) Frans Janszoon Post un artista expedicionario conocido por pintar los paisajes de Sudamérica, concretamente de la zona de Pernambuco, en Brasil y el delta del río São Francisco y en cuyos bodegones es posible encontrar frutos que todavía no habían llegado a Europa como el Bodegón

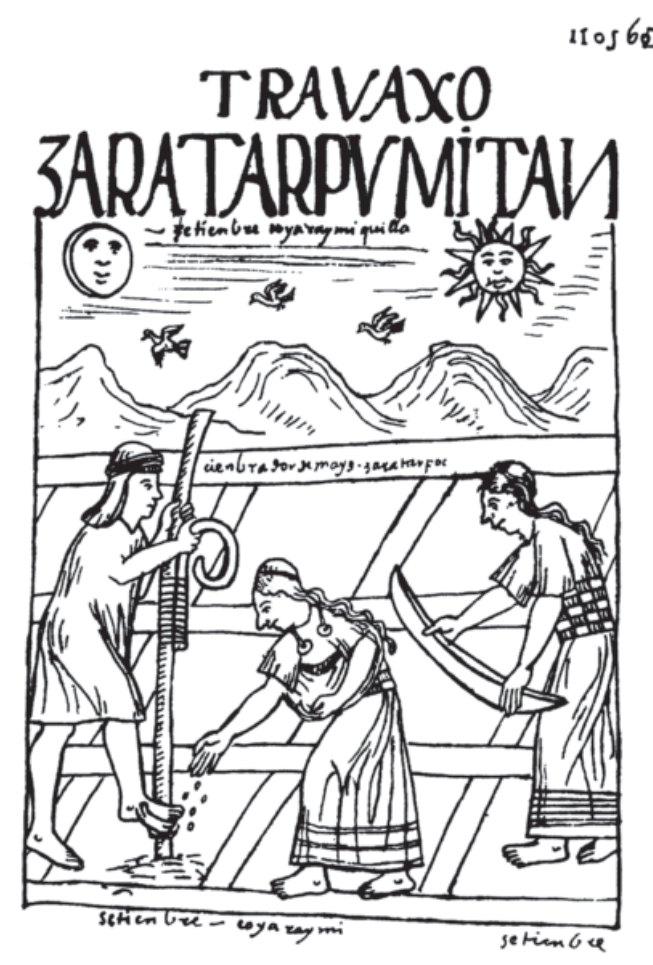

Figura 1. Guaman Poma de Ayala - El primer nueva corónica y buen gobierno (1615-1616). Fuente: Det Kongelige Bibliotek. 
con yuca o Bodegón con cocos, piña papaya y otras frutas. Especialmente con la piña hay un relación especial ya que su consumo era un símbolo de estatus social debido a la complejiadd de su domesticación de la Inglaterra del s.XVIII en el Fitzwilliam Museum podemos encontrar la obra Pineapple grown in Sir Matthew Decker's garden at Richmond, Surre de, Theodorus Netscher (Burdeos, 1661-Hulst, 1728) una de la primera representaciones visuales de la piña (Figura 2).

En la segunda mitad de la Edad Moderna la comida irrumpe en las arte especialmente en la pintura bien por las escenas representando banquetes, estaciones del año, bodegones, escenas de caza, mercados, interiores de cocina o mesas delicadamente puestas con manteles donde se aprecia las marca de la piegatura una técnica desarrollada sobre todo en conventos en que los manteles eran exquisitamente plegados y cuyas marcas eran un elemento decorativo como la que se puede apreciar en el El encuentro de San Francisco de Asís y Santo Domingo de Guzmán y el Milagro en el refectorio, óleo de1644 Felipe Gil de Mena que se puede apreciar en el Museo Nacional de Escultura de Valladolid.

Mientras en Europa la pintura de bodegón se consolidaba como un género propio y que aparezcan representadas en ellas en varias ocasiones cajas de dulces y mermeladas no es de extrañar ya que la conservación de alimentos siempre ha despertado el interés de científicos

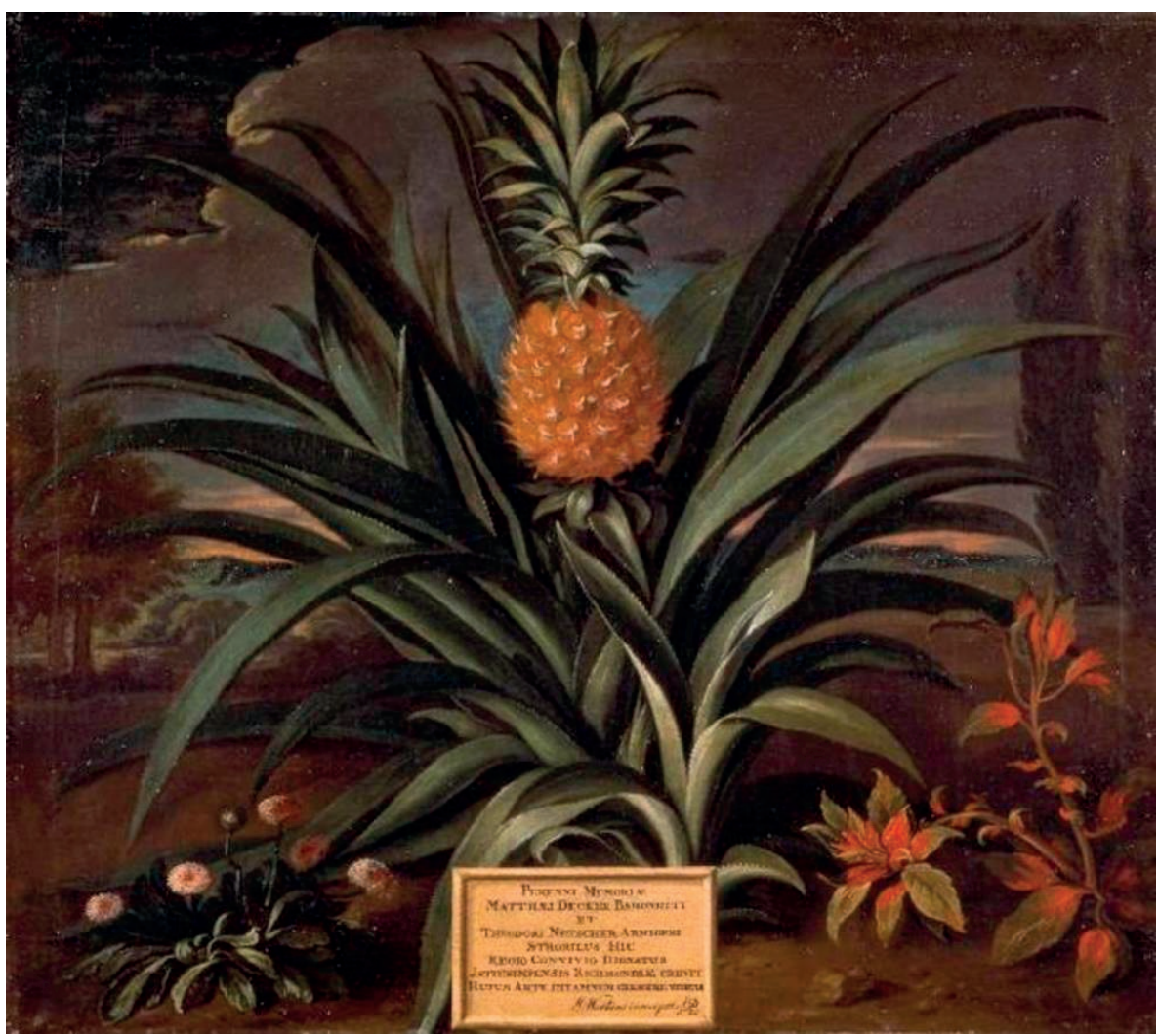

Figura 2. Pineapple grown - Theodorus Netscher (1661-1728). Fuente: Fitzwilliam Museum. 
del momento y en 1654 Nicolas de Bonefons publica Le jardinier français y en su segunda parte constituye todo un tratado sobre los procedimientos de conservación de las frutas por medios de azúcar, clasificándolas en dos tipos "las mermeladas secas y las mermeladas liquidas y las secas. Estas técnicas novedosas en el siglos XVII constituye toda una revolución en la mesa, debido a la popularización por las clases dirigentes de toda Europa de los productos provenientes de América y que el postre como parte de un servicio era casi un requisito fundamental en cualquier banquete y un regalo real con que muchos monarcas obsequiaban a sus agasajados. Así podemos encontrar obras como Bodegón con manzanas, nueces, cajas de dulces y otros recipientes de1759 de Luis Egidio Meléndez, (1716-1780) en que se observan esas cajas de dulces.

Mientras que en las obras de una gran bodegonista como fue Clara Peeters encontramos referencias a las pautas culinarias y los modos de compartir los alimentos en la época. Y sobre dodo platos preparados. Así el consumo de sal era un producto que en las clases acomodadas de la aristocracia de los Países Bajos alcanzaba el grado de distinción social. En obras como Mesa con mantel, salero, taza dorada, pastel, jarra, plato de porcelana con aceitunas y aves asadas (Hacia 1611), un salero que pintara en otras obras. Este salero era una pieza de moda en la época ya que los volvemos a ver en la obra Fin de una colación de 1637 Willem Claesz Heda también de los Países Bajos.

La historia de la alimentación es también la historia del hambre no todas las representaciones corresponden a la abundancia. Artistas como Velázquez y Murillo dedicaron varias obras con lo que consiguieron retratar con extraordinaria maestría la forma de comer y que comían el campesinado o las personas al margen de la nobleza. Vieja friendo huevos y Niños comiendo melón y uvas respectivamente muestra desde el costumbrismos otras realidades alimentarias al margen de la que retrata el bodegón. Hay que resaltar que los bodegones especialmente eran destinados para el comedor de la aristocracia y la monarquía y que acompañaba a los aparadores donde se exhibía la vajilla que se iba utilizar como se puede apreciar en algunas obras que se visualizan comedores.

Con respecto a la escases hay que destacar que obras como las cuatro estaciones pintadas por Giuseppe Arcimboldo por encargo de Maximiliano /l de Habsburgo en 1573 aparece el maíz lo que hace suponer que ya se había popularizado su consumo en Europa paliando en ciudades como Venecia la gran hambruna vivida en 1528. No es casualidad que el pintor milanés le dedicara en su composición un lugar preferente ya que este producto llegado de ultramar había paliado el hambre en las hambrunas de años anteriores.

El ejemplo más claro de la representación de la polenta es la obra del pinto veneciano Pietro Longhi (1701-1785) obra pintada en 1740 y que refleja el interior de lo que podría ser una taberna donde dos mujeres ofrecen a dos músicos el suculento plato surgido en plena pandemia unas décadas antes.

La polenta no era la única comida de pobres anterior a la polenta la elaboración de gachas era común la pintura La boda de campesina fechada en 1568 de Pieter Brueghel el Viejo se pueda ver la comida de los pobre también algo parecido a la polenta o gachas que se sirve en el banquete quizás no de maíz como aconteció en Italia sino de trigo u otro cereal ya que de unas de las paredes del granero donde se celebra la boda se puede apreciar espigas como referencia el tiempo estival cuando ocurre la ceremonia. 
En América el maíz ya había sido representado sobre el 600 dC en el yacimiento arqueológico de Cacaxtla donde se encontraron mazorca de maíz tanto de cerámicas o representadas en murales o los mismos depósitos de grano, pero en Europa estas representaciones no fueron posible hasta la aclimatación primero de la semilla y luego de su cultivo, domesticación, producción de semillas y popularización entre el campesinado. Un proceso que entre la llegada de tierras de ultramar por Colón, una crisis alimentaria y sanitaria, la extensión de la semilla por Europa, la llegada a Italia y hasta la obra de Longhi acontecieron unos 250 años. Hoy existen en la Lombardía festivales dedicados a la polenta como seña de identidad y altocultural en el que se le rinde homenaje en banquetes colectivos a este alimento de la escases.

El alimento en las artes tiene sobre todo en este periodo, un gran valor para documentar la utilización de determinados alimentos y utensilios, o la domesticación de nuevas especies como el tomate que lo encontramos por primera vez representado en una pintura como es La cocina de los Ángeles de 1646 de Esteban Murillo que se encuentra en el Louvre y en el que un pequeño tomate aparece entre calabazas.

El siglo XVIII va a ser un momento muy rico en la producción visual de elementos pictóricos de la alimentación por la proliferación de recetarios, protocolo, normas de uso, tratados de saludos algunos citados anteriormente. Francia se consolida como la gran potencia gastronómica Europea y va a ser desde donde partan las normas y las modas para el resto de Europa. La producción visual de esa época estará en cosas tan dispares como las normas para doblar servilletas de lo que existen auténticos tratados hasta la pintura en donde se representan fastuosos banquetes y se puede apreciar ostras, champagne y hielo que era un producto solo utilizado por la alta aristocracia detalle que se pueden apreciar en la pintura de Jean François de Troy, The Oyster Lunch hacia 1735 depositada en el Chantilly Musée Conde.

Sin haber seguido un orden por periodos históricos, sino más bien centrado en el tipo de alimentos y su importancia para la sociedad y la difusión de su consumo y el número importante de imágenes que generó, es posible construir, de manera en algunos casos cronológica y en otro momento temática sobre el comer y lo que le rodea nos adentramos en el siglo XIX. En este momento la producción visual relacionada con la alimentación va estar dedicada a la comida como elemento plástico aunque hay verdaderas obras que permiten documentar la forma de comer de la época. La pintura se mezcla con la publicidad y las fuentes visuales son variadas desde las publicidades de bebidas alcohólicas hasta la representación de espacios de comercialización de alimentos como bares, mercados, tabernas o mesones.

En la historia reciente sobre todo durante el siglo XX y parte del siglo XXI la publicidad relacionada con los alimentos nos permite analizar como han ido cambiando los gustos en relación con los alimentos la cada ve más creciente utilización de productos alimentarios industriales y como nuevas técnicas de elaboración como la deshidratación y lo instantáneo ha surgido a partir de la segunda Guerra Mundial para dotar a los soldados de alimentos en el frente.

Con las vanguardias a principio del siglo XX y todo el arte posterior a este movimiento y también en el arte contemporáneo actual la comida transmuta como fuente de documentación y se transforma en un elemento para la denuncia, la provocación o la reflexión. Hoy en las reproducciones artísticas la alimentación sigue presente documentando otros aspectos de la cultura contemporánea como las obras del artista Herny Hargreaves que denuncia la pena de muerte por medio de la última comida pedida por los reos reproducida y luego fotografiada acompañada 
de la información de la víctima. Son muchos los artistas actuales en que los alimentos se transforman en sus manos en un elemento plástico como la obra Bread Hause de 2004-2006 del artista Urs Fisher una casa completamente construida en pan, o las grandes hamburguesas de Tom Friedman denunciando el impacto de la comida rápida.

Finalmente cabe decir que se ha producido una alternancia de la pintura, las ilustraciones históricas en guías botánicas o escritos de viajes llegados del viejo mundo como fuente de documentación de la alimentación a la obra artística como fuente de reclamo sobre algún tema social en concreto, ya no documenta procedencia de un alimento, zona de consumo sino un discurso mucho más complejo y tentacular sobre distintos aspectos de la cultura contemporánea en temas relacionado con el hambre, la exclusión social, la obesidad, el desperdicio de alimentos, el cambio climático o como en el caso lejanos a la alimentación como la pena capital aún presente en algunos estados de Estados Unidos.

La producción visual relacionada con la alimentación permite la producción material de la alimentación de otras épocas. El especialista en la historia de la alimentación Ivan Day por medio de la documentación pictórica y de otras fuentes documentales recrea los platos comidos por la monarquía y la alta aristocracia. Su casa museo es un auténtico laboratorio de reproducción de la comida de tiempos pasados.

El valor de las imágenes para la construcción de una historia ya no visual sino también física de la alimentación como la recreación de algunos platos ha quedado demostrada en la exposición Fiesta y ayuno: el arte de la comida en Europa entre 1500 y 1800 en el Fitzwilliam Museum, Cambridge, en esta exposición multisensorial se exhibieron piezas de gran valor conservados en el Fitzwilliam Museum y otras colecciones. En la exposición se presentaba cuatro espectaculares reconstrucciones históricas con comida en su centro, incluido un banquete de azúcar jacobeo, una mesa de banquete europea y un taller de repostería georgiano. Por medio de piezas y documento se pudo descubrir temas contemporáneos y no libre de controversias, como los orígenes de la alimentación y la seguridad alimentaria, el consumo excesivo en tiempos de austeridad y nuestra relación con los animales y la naturaleza, vinculando así el pasado con nuestro presente y alentando a los visitantes a cuestionar y repensar nuestra relación con la comida.

Toda representación visual es usada para la que en nuestra cabeza se produzca un representación de la comida en tiempos pasados y también presentes en muchos museos dedicados a la alimentación utilizan por medio de reproducciones en paneles explicativos o facsímiles estas imágenes y esto permite que como espectadores construyamos un ideario de la comida en tiempos pasados.

\section{Resultados}

Luego de observar obras visuales de diferentes procedencias es posible constar la estrecha relación que existe entre la historia de la alimentación y la historia el arte incluida la fotografía y la publicidad. Podemos decidir hablar de arte como documento y documento como si obra de artes se tratase. Las obras artísticas producidas en Europa tuvieron inmediatamente el tratamiento de obras artísticas y con el surgimiento de la historia de la alimentación en documento de constatación sobre comensalidades y alimentos. 
Mientras que los documentos llegados de las colonias han sido tratados como meros documentos antropológicos e históricos sobre el modo de ser de los pueblos originarios de América. Esta colonialidad no solo de los manuscritos, los libros de viaje, o las obras compilatorias sobre especies animales y vegetales sino también de las obras artísticas de movimientos como el Barroco Virreinal ha fortalecido la diferenciación entre lo estrictamente artístico y lo documental de las obras artísticas creadas en América.

En donde mayor utilidad se le da al valor del uso de imágenes sobre la alimentación adquiere es en los museos de la alimentación transformándose en auténticas piezas visuales que permiten construir y sostener un relato sobre la alimentación. En los museos visitados es común en los de vocación vinícola representaciones de la eucaristía el uso de imágenes donde aparecen vides o elementos escultóricos de templos en donde se hacen claras referencias al vino para sostener un relato que la región tiene una larga e histórica vocación vinícola. O como en el Museo del Pimentón de la Vera de Jaráiz de la Vera en donde la colección de latas de pimentón puede apreciarse el diseño gráfico y la publicidad en el siglo pasado o finalmente como la recolectora de miel de Bicorp una auténtica pieza de gran valor no sólo arqueológico sino documental que es usada en el Museo Valenciano de la Miel para explicar que en la zona se recogía miel de tiempo pretéritos.

Este uso de la imagen relacionada con la alimentación como testimonio de la existencia de un producto en una época determinada no sólo es usado como recurso visual en los museos dedicados a la alimentación sino también en las obras compilatorias sobre la comida y en ocasiones hasta en las mismas etiquetas y publicidad de los productos.

\section{Conclusiones}

La comida sigue produciendo imágenes de gran potencia visual y simbólica lo que demuestra es que ya no es una fuente de documentación para la construcción de un relato ordenado de la Historia de la alimentación como lo fue sobre todo al comienzo de Edad Moderna con el descubrimiento y colonización de América y hasta la revolución industrial. La publicidad relacionada con algunos alimentos propia del siglo XIX hasta la actualidad está permitiendo documentar la gran velocidad que acontecen los cambios alimentarios, la globalización alimentaria en la que nos encontramos inmersos, la homogeneización de los gustos y las consecuencias de la producción a gran escala de alimentos para el medio ambiente. Esto ultimo lo esta referenciando y representando el arte contemporáneo que usa la comida como elemento para promover la subversión y el debate sobre determinadas prácticas alimentarias.

Las disciplinas próximas a la comunicación visual no se han detenido en el estudio sobre el uso de las imágenes en cualquier formato y de cualquier origen para la investigación en el campo de la historia de la alimentación y es un campo de estudio a explorar y que permitirá enriquecer, comprender y analizar nuestro devenir alimentario.

Las producciones visuales relacionadas directa o indirectamente en cualquier formato e intencionalidad son la bases en que todo especialista de la cultura de la alimentación debe indagar para la elaboración de un relato sobre la comida, sean estas artísticas, publicitarias o meros objetos decorativos o funcionales vinculados con la comida son como nuestra huella histórica sobre que hemos comido, como lo hemos comido y con quién compartíamos nuestros alimentos y sobre todo una forma casi de arqueología visual de la alimentación. 
Además hay que analizar sobre todo en la en la última mitad del siglo XX y hasta la actualidad el metadiscurso que se esconde debajo de los alimentos. De la misma manera que sobre las marcas de los raspadores dejadas por esos "monos que cocinan" sobre los huesos encontrados en los yacimientos paleontológicos como el de Atapuerca una publicidad de una tostadora de mediados de los 40 es un documento visual de extraordinario valor para construir un relato no solo cronológico si no también visual de la alimentación para encontrar pistas sobre quienes cocinaban, porque lo hacía y debido a que discurso.

\section{Bibliografía}

\section{Libros}

Avery, V., \& Calaresu, M. (2020). Feast \& Fast: The Art of Food in Europe, 1500-1800. London: Philip Wilson Publishers.

De Ayala, F. G. P., \& GY, F. P. (1980). Nueva corónica y buen gobierno (Vol. 1). Fundación Biblioteca Ayacuch.

Montanari, M., \& Lima, M. D. F. F. D. (2009). Comida como cultura. Madrid: Ed. Trea, SL

Montanari, M., \& Flandrin, J. L. (2011). Historia de la alimentación. Madrid: Ed. Trea, SL.

Wrangham, R. (2009). Catching fire: how cooking made us human. California: Basic Books.

\section{Peliculas}

Vatel (Roland Jofré) Coproducción Reino Unido-Francia. 2000. 